\title{
LAS NUEVAS FACULTADES DEL TRIBUNAL CONSTITUCIONAL PARA ASEGURAR EL CUMPLIMIENTO DE SUS RESOLUCIONES
}

The new faculties of the Constitutional Court to ensure the fulfillment of his resolutions

\author{
GERMÁN FERNÁNDEZ FARRERES \\ Universidad Complutense de Madrid \\ gffarreres@der.ucm.es
}

Cómo citar/Citation

Fernández Farreres, G. (2018).

Las nuevas facultades del Tribunal Constitucional

para asegurar el cumplimiento de sus resoluciones.

Revista Española de Derecho Constitucional, 112, 15-44.

doi: https://doi.org/10.18042/cepc/redc.112.01

\section{Resumen}

En el presente trabajo se analizan las nuevas facultades atribuidas al Tribunal Constitucional para garantizar el cumplimiento de sus sentencias y resoluciones. La atribución de tales facultades (la suspensión de autoridades o empleados públicos, la ejecución sustitutoria y la adopción de las medidas de ejecución inaudita parte), además de la multa coercitiva prevista desde el primer momento, han generado una importante polémica en la doctrina y en el seno del propio Tribunal Constitucional. La conclusión a la que se llega es que la reforma, aun no siendo imprescindible, no merece los reproches que contra la misma se han formulado.

\section{Palabras clave}

Tribunal Constitucional; ejecución de sentencias; medios de compulsión; multa coercitiva; suspensión de autoridades o empleados públicos; ejecución sustitutoria de resoluciones judiciales. 


\section{Abstract}

The present work analyzes the new faculties attributed to the Constitutional Court to guarantee the fulfilment of his judgments and resolutions. Such attributions (the suspension of public authorities or employees, the substitute enforcement and the adoption of enforcement measures inaudita parte) and the coercive fine recognized from the beginning, have generated an important polemic in the doctrine and in the Constitutional Court itself. The conclusion is that the reform, while not being essential, does not deserve the criticisms that have been made against it.

\section{Keywords}

Constitucional Court; execution of sentences; compulsion methods; coercive fine; suspension of authorities or public employees; substitute execution of judicial resolutions. 
I. INTRODUCCIÓN. II. UNA PRECISIÓN SOBRE LA «DESNATURALIZACIÓN» DE LA JURISDICCIÓN CONSTITUCIONAL. III. LAS NUEVAS FACULTADES DE EJECUCIÓN, INCLUIDA LA MULTA COERCITIVA, Y EL PRINCIPIO DE LEGALIDAD PENAL. IV. LA SUSPENSIÓN DE AUTORIDADES O EMPLEADOS PÚBLICOS. V. LA EJECUCIÓN SUSTITUTORIA. VI. LA ADOPCIÓN DE LAS MEDIDAS INAUDITA PARTE. VII. OTRAS NOVEDADES. VIII. CONSIDERACIÓN FINAL. BIBLIOGRAFÍA.

\section{INTRODUCCIÓN}

La Ley Orgánica 15/2015, de 16 de octubre, de reforma de la Ley Orgánica del Tribunal Constitucional, para la ejecución de las resoluciones del Tribunal Constitucional (TC) como garantía del Estado de derecho, ha incorporado tres novedades destacadas al elenco de facultades que el Tribunal tiene atribuidas para la garantía del cumplimiento de sus resoluciones. En adelante, ante los incumplimientos, una vez constatados tras los correspondientes requerimientos a los responsables de los mismos, podrá acordarse la suspensión en sus funciones de las correspondientes autoridades o empleados públicos, podrá procederse a la ejecución sustitutoria de las resoluciones recaídas en los procesos constitucionales y, asimismo, podrán adoptarse inaudita parte las medidas necesarias para asegurar el debido cumplimiento de la suspensión de las disposiciones, actos o actuaciones impugnadas, cuando concurran circunstancias de especial trascendencia constitucional.

Estas nuevas atribuciones han generado una importante polémica en la doctrina y en el seno del propio Tribunal que, además, ha alcanzado a las multas coercitivas, las cuales, aunque previstas desde el primer momento por la LOTC de 1979, en momento alguno habían sido cuestionadasª .

En cuanto a las demás novedades de la reforma (aplicación supletoria de la LJCA, notificación personal de las resoluciones y la consideración de títulos ejecutivos de las sentencias y resoluciones del Tribunal), lo cierto es que son de bastante menos alcance y relevancia.

1 No obstante, como se ha recordado en el ATC 170/2016, de 6 de octubre, tampoco el Tribunal tuvo ocasión de recurrir a ellas para asegurar el cumplimiento de sus resoluciones. 
La reforma trae causa de la proposición de ley del Grupo Popular del Congreso de los Diputados, planteada durante la precampaña de las elecciones de Cataluña de septiembre de 2015. El dato no puede pasar desapercibido. No mediando el "problema catalán», la reforma no se habría planteado. Aunque no se mencione expresamente, la propia justificación de la proposición de ley lo evidencia: «[...] la necesidad de adaptarse a las nuevas situaciones que pretenden evitar o soslayar tal efectividad [de las decisiones del Tribunal Constitucional] obliga a desarrollar los instrumentos necesarios para que la garantía de efectividad sea real». Y es que en esas fechas, el desafío independentista de las autoridades catalanas, dispuestas, entre otras acciones, a desobedecer frontalmente las sentencias y resoluciones del TC, ya se había puesto de manifiesto. Una circunstancia que ha sido resaltada por la doctrina, prácticamente sin excepción, y sobre todo por el magistrado Xiol Ríos en los votos particulares que formulara a las SSTC 185/2016, de 3 de noviembre, y 215/2016, de 15 de diciembre, resolutorias de los recursos de inconstitucionalidad planteados contra dicha ley orgánica por el Gobierno vasco y la Generalidad de Cataluña ${ }^{2}$. Todo lo cual explica, por otra parte, la urgencia por acometer la reforma y, en consecuencia, que la tramitación de la correspondiente proposición de ley lo fuese en lectura única, lo que no ha dejado de ser cuestionado, si bien las referidas sentencias han desestimado las tachas de inconstitucionalidad planteadas ${ }^{3}$.

Importa dejar claro, por tanto, que, al igual que sin la Sentencia de la Sala Primera del Tribunal Supremo de 23 de enero de 2004, que condenó a once magistrados constitucionales por responsabilidad civil derivada del ejercicio de sus funciones jurisdiccionales, no habría sido necesaria la reforma de $2007^{4}$, sin

2 Ello le lleva a criticar la decisión del TC de abordar en primer lugar el análisis del último de los recursos planteados —el del Gobierno del País Vasco-, en detrimento del primero — el de la Generalitat de Cataluña—, pues, con sus propias palabras, «no es difícil adivinar, sin embargo, que esas nuevas situaciones que pretenden evitar o soslayar la efectividad de las resoluciones del Tribunal Constitucional están en directa relación con diversas decisiones adoptadas por la Generalitat y, especialmente, por el Parlament de Catalunya [...]».

3 No se puede olvidar, de todas formas, que también se han tramitado por este procedimiento la reforma constitucional del artículo 135 CE (el ATC 9/2012, de 13 de enero, inadmitió el recurso de amparo planteado frente a los acuerdos de la mesa del Congreso relativos a la tramitación de la proposición de reforma constitucional) y el proyecto de ley orgánica por el que se hizo efectiva la abdicación de su majestad el rey Juan Carlos I de Borbón (Ley Orgánica 3/2014, de 18 de junio).

4 Recuérdese que con la finalidad de preservar y reforzar la jurisdicción constitucional, a la redacción inicial del apdo. 1 del art. 4 LOTC («En ningún caso se podrá 
el asunto catalán de por medio seguiríamos tranquilamente con la redacción inicial del art. 92 de la LOTC de 1979. Una regulación que a lo largo del tiempo se ha mostrado suficiente para dar respuesta a los incidentes de ejecución planteados, los cuales, por lo demás, han sido más bien escasos, apenas medio centenar en casi cuarenta años ${ }^{5}$.

Por otra parte, debe ya advertirse que las dudas de inconstitucionalidad que la reforma ha suscitado han quedado despejadas por las SSTC 185/2016, de 3 de noviembre, y 215/2016, de 15 de diciembre, en los términos que de inmediato se verán. Y debe igualmente señalarse que, al menos por ahora, las nuevas atribuciones han servido para poco, prácticamente para nada, dado que no se ha hecho uso de la suspensión de funciones de autoridades o empleados públicos de la Administración responsable del incumplimiento, ni se ha adoptado medida de ejecución sustitutoria alguna. Tras la aprobación de la Ley de reforma, el TC ha conocido de varios incidentes de ejecución, resueltos por los Autos 141/2016, 170/2016, 24/2017, 124/2017 y 126 y 127/2017. Pero, a excepción de estos dos últimos, en los que ha hecho uso de la multa coercitiva y, además, lo ha hecho inaudita parte, al amparo del nuevo art. 92.5 - un uso, por cierto, que sí ha demostrado la eficacia de la medida—, en todos los demás casos se ha limitado a advertir una y otra vez, a formular admoniciones con perseverancia y sin desmayo de que sus resoluciones se han de cumplir, pero ante la recalcitrante negativa a hacerlo por las autoridades catalanas no

promover cuestión de jurisdicción o competencia al Tribunal Constitucional») se incorporó el inciso «el Tribunal Constitucional delimitará el ámbito de su jurisdicción y adoptará cuantas medidas sean necesarias para preservarla, incluyendo la declaración de nulidad de aquellos actos o resoluciones que la menoscaben», añadiéndose en el apdo. 3 que «cuando el Tribunal Constitucional anule un acto o resolución que contravenga lo dispuesto en los dos apartados anteriores lo ha de hacer motivadamente y previa audiencia al Ministerio Fiscal y al órgano autor del acto o resolución». Y esta última previsión quedó reiterada con un nuevo apdo. 2 del art. 92, en virtud del cual el Tribunal Constitucional "podrá también declarar la nulidad de cualesquiera resoluciones que contravengan las dictadas en el ejercicio de su jurisdicción, con ocasión de la ejecución de éstas, previa audiencia del Ministerio Fiscal y del órgano que las dictó». Como ha señalado el ATC (Pleno) 141/2016, de 19 de septiembre, «[...] conforme a la jurisprudencia constitucional (entre otros, AATC 107/2009, de 24 de marzo, f.j. 2; y 177/2012, de 2 de octubre, f.j. 2) los artículos 87.1 —párrafo primero- - y 92 LOTC tienen por finalidad garantizar la defensa de la posición institucional del Tribunal Constitucional y la efectividad de sus sentencias y resoluciones, protegiendo su ámbito jurisdiccional frente a cualquier intromisión ulterior de un poder público que pudiera menoscabarla».

5 El dato en Villaverde Menéndez (2016: 644). 
ha recurrido a ninguna de las nuevas atribuciones. Solo ha acudido finalmente a dar traslado del oportuno testimonio de particulares para exigir la responsabilidad penal que pudiera corresponder a la presidenta y algunos miembros de la Mesa del Parlamento de Cataluña ${ }^{6}$.

Cabe añadir, por último, que, la reforma ha facilitado la apertura de un nuevo frente de discusión que en poco ayuda al Tribunal, tocado como lo está en su auctoritas desde hace ya unos cuantos ańos. Aunque ha contado con alguna opinión doctrinal favorable, destacadamente la de Ignacio Díez-Picazo (2017), en líneas generales ha propiciado una riada de críticas un tanto innecesarias para la propia imagen del Tribunal'. Por mucho que la mayoría de ellas hayan sido absolutamente excesivas y un tanto infundadas, la realidad es que ahí están. Incluso, se ha llegado a decir, aunque con una ligereza asombrosa, que la reforma supone una "grosera reconversión del TC en una suerte de Tribunal administrativo y sancionador de Orden Público» y que la misma se «encarama de inmediato al podio de las menos calculadas y más deplorables de toda la historia democrática desde la Constitución de 1978», pues «pretende inyectar, y encapsular, a capón, en el cuerpo del TC, una función policial y sancionadora de "emergencia" notoriamente extraña a su naturaleza y funciones [...] ${ }^{8}$. Y hasta en el propio seno del Tribunal, en los votos particulares de los magistrados discrepantes de las SSTC 185 y 215/2016, los términos empleados para mostrar la discrepancia con la mayoría no dejan de sorprender por su dureza. En las expresiones de los magistrados constitucionales no es frecuente, afortunadamente, encontrar descalificaciones tan rotundas, ni expresiones tan coloquiales, como las que se contienen en tales votos?

6 Conviene observar, de todas formas, que el Gobierno de la nación, a excepción de la multa coercitiva, tampoco ha solicitado del Tribunal que adoptase alguna de esas medidas, a pesar de que, a la vista de los incumplimientos de las resoluciones que han dado lugar a los correspondientes incidentes, podía estar más que justificada la solicitud. El Gobierno, por tanto, no ha puesto al TC en el compromiso de tener que descender a la «ladera de lo fáctico» y pronunciarse sobre la pertinencia e idoneidad del uso de las medidas de ejecución o compulsión previstas para la garantía de la observancia y cumplimiento de sus resoluciones.

7 Entre otras, Cámara Villar y Montilla Martos (2015), Roig Molés y Nieva Fenoll (2017), Ridao Martín (2016: 52 y ss.) y (2017: 151 y ss.); también, aunque algo más contenidas, Almeida Cerrada (2017: 66 y ss.).

8 Véase López Aguilar (2016: 304-305).

9 Valga la siguiente muestra. La magistrada Asúa, al referirse a las tachas alegadas por la representación procesal de la entidad recurrente, afirma que «su gravedad y la posición jurídica que ocupa la norma impugnada en el ordenamiento constitucional le obligaban a este Tribunal a tratarlas con la debida seriedad». Afirma en otro momento 
Todas estas circunstancias, en definitiva, en nada favorecen a un tribunal tan necesitado de recuperar el prestigio y la autoridad que en sus primeros ańos logró de manera indiscutible y que, sin embargo, poco a poco se ha ido diluyendo ${ }^{10}$.

\section{UNA PRECISIÓN SOBRE LA «DESNATURALIZACIÓN» DE LA JURISDICCIÓN CONSTITUCIONAL}

Antes de proceder al comentario de las referidas novedades, conviene decir algo sobre si la atribución de tales facultades conlleva una "desnaturalización» de la jurisdicción constitucional. Y digo «jurisdicción constitucional» con naturalidad, aunque en el voto particular de la magistrada Asúa Batarrita se resucita la vieja cuestión de la naturaleza jurisdiccional del Tribunal Constitucional que parecía estar definitivamente superada. En su opinión, «la afirmación de la Sentencia sobre la naturaleza jurisdiccional del Tribunal Constitucional y la facultad de ejecución como "cualidad inherente" a la función de administrar justicia, "también de la justicia constitucional", constituye un grave error conceptual de partida». Y aún añade que «la ejecución de

que «a lo largo de la Sentencia se repite como un mantra que el constituyente no quiso que fuera "un modelo cerrado" [...]» y que «la respuesta del Tribunal Constitucional ante esta impugnación —algo así como "lo veremos cuando llegue el momento" - es, por tanto, insólita». Añade que «cuando, excepcionalmente, la Sentencia de la que disiento entra a examinar las graves tachas de inconstitucionalidad que alega el recurso de inconstitucionalidad, las despacha con afirmaciones superficiales y apodícticas» y que «el análisis que [la sentencia] realiza sobre el carácter punitivo o no de la suspensión de funciones resulta muy rudimentario: todo se reduce a atribuirle a la suspensión una función no punitiva de forma apodíctica y reiterativa». Reitera, en fin, que «no resulta admisible que, [...], el análisis que se despliega en la Sentencia sea tan pobre» y hasta considera que «el Tribunal Constitucional ha abdicado de su cometido esencial, la custodia de la Constitución, ante implícitas urgencias de Estado». Por si no fuera suficiente, el magistrado Valdés incluso va más lejos: «No ha sido ésta, sin embargo, la premisa metodológica manejada por la opinión mayoritaria que apoya la sentencia de la que me aparto, que instala su argumentación jurídica en un criticable autismo». Y el magistrado Xiol califica de «falacia argumental» el razonamiento de la sentencia acerca de que el control abstracto no le permite ir más allá en el enjuiciamiento.

10 En este punto, no puedo dejar de recordar la advertencia de Francisco Tomás y Valiente (1997: 2284): «Las instituciones ganan o pierden prestigio por lo que hacen, pero también por lo que con ellas se hace». 
las sentencias constitucionales no es en absoluto una atribución inherente al elenco de competencias de un Tribunal Constitucional, sino una decisión que puede adoptar el constituyente y, en su defecto, si aquel así lo permite, el legislador orgánico $[\ldots] »$.

Sin embargo, no creo que estemos ante ningún «grave error conceptual». Por el contrario, la indiscutible naturaleza jurisdiccional de la función que corresponde al Tribunal Constitucional conduce directamente a reconocer que esa función jurisdiccional tiene que estar acompañada de la función de velar por que sus resoluciones se cumplan. La potestad de ejecución resulta de la propia posición constitucional del Tribunal y de su función de garante jurisdiccional último de la supremacía constitucional. Y por ello nada obsta a que esa potestad de ejecución sea considerada una de las «materias» a las que se refiere la letra d) del art. 161.1 CE y que, como es natural, puede regular la LOTC. La dicción del art. 161.1.d) CE habilita sin duda al legislador orgánico para regular una función que no puede dejar de considerarse inherente a la jurisdicción constitucional.

Cuestión distinta es, obviamente, que las peculiaridades de esta jurisdicción puedan si acaso llevar a una modulación de las normales facultades reconocidas a jueces y tribunales para hacer cumplir lo juzgado. Pero que así sea para nada permite negar la condición jurisdiccional del Tribunal, ni tampoco permite concluir que no deba disponer de poderes de ejecución.

La explicación y respuesta dada por las SSTC 185 y 215/2016 al alegato de que, al no preverse nada de manera expresa al respecto en la Constitución, la Ley Orgánica de reforma se habría excedido, me parecen más que suficientes para poder dar por zanjada esta primera objeción de carácter general, una especie de enmienda a la totalidad que no presenta mayor consistencia. Baste recordar un fragmento del f. j. 10 de la STC 185/2016: "Las concretas medidas contempladas en el art. 92.4 b) y c) y 92.5 LOTC constituyen, al igual que el resto, instrumentos o potestades puestos a disposición del Tribunal por el legislador para garantizar el debido y efectivo cumplimiento de sus sentencias y demás resoluciones, al que están obligados todos los poderes públicos, incluidas las Cámaras legislativas (ATC 170/2016, de 6 de octubre, f.j. 2). La finalidad perseguida con ellas, [...] es preservar la supremacía de la Constitución, a la que todos los poderes públicos están subordinados (art. 9.1 CE), y cuyo supremo intérprete y garante último es este Tribunal en el ejercicio de su función jurisdiccional». A lo que se añade: «No puede afirmarse que estas medidas [...] alteren, por sí mismas, [...] las funciones del Tribunal Constitucional» $\mathrm{y}$ «la autonomía parlamentaria no puede erigirse en razón para soslayar el cumplimiento de las resoluciones del Tribunal Constitucional», sin que la admonición a cumplir sus resoluciones suponga «en modo alguno una 
restricción ilegítima» de aquella autonomía «ni comprometa el ejercicio del derecho de participación de los representantes políticos garantizado por el art. $23 \mathrm{CE}$ ", pues «es la consecuencia obligada de la sumisión a la Constitución de todos los poderes públicos (art. 9.1 CE)».

No puede desconocerse, por otra parte, que el Tribunal es, en expresión de la doctrina alemana que ha hecho fortuna, el «seńor» de la ejecución ${ }^{11}$ y, por tanto, a él corresponde administrar el ejercicio de las facultades de que dispone, valorando ante cada caso si procede o no hacer uso de las mismas y acudiendo, si lo fuese, a la más idónea y apropiada. Y aunque pudiera considerarse, tal como lo hace el magistrado Xiol en su voto a la STC 185/2016, que estamos en presencia de verdaderas potestades que, en consecuencia, por su naturaleza y condición no pueden dejar de ser ejercitadas ${ }^{12}$, ello no empece para que el Tribunal goce de un amplio margen de apreciación para tomar la correspondiente decisión, determinando, además, el medio de ejecución que, si procediere, considere idóneo, más adecuado e, incluso, oportuno. Por eso, en sus resultados prácticos, el Tribunal no deja de ser «dueño de la ejecución».

Por último, la utilización de este tipo de medida, para nada «desdibuja la naturaleza primaria del Tribunal como un órgano jurisdiccional al que se le confiere la jurisdicción constitucional $»^{13}$. Sin poner en duda que la fuerza

11 Se hace eco de la expresión «señor de la ejecución» (también «señor del proceso») Arzoz Santisteban (2016: 26); igualmente, Villaverde Menéndez (2016: 645).

12 Recordaré literalmente su razonamiento: «Habiéndose configurado legalmente como verdaderas potestades del Tribunal Constitucional, tampoco en el marco de ese incidente de ejecución se podría optar por su no ejercicio por razones de oportunidad. Una vez determinada la existencia del incumplimiento, ninguna posibilidad elusiva tiene el Tribunal Constitucional para no adoptar una de ellas. El único margen de discrecionalidad con el que cuenta es, dentro de un necesario juicio de proporcionalidad, seleccionar la medida de ejecución que debe adoptarse. Constituye una grave distorsión pensar que el Tribunal, una vez reconocidas las potestades de ejecución que la Ley le atribuye "puede o no" ejercitarlas; la realidad es que «debe» ejercitarlas si concurren los presupuestos para ello".

13 Así lo afirman los magistrados Valdés y Xiol y la magistrada Balaguer en su voto particular concurrente a los AATC 126 y 127/2017, de 20 y 21 de septiembre. Y añaden: "La fuerza ejecutiva de nuestras sentencias y autos deriva de dicha auctoritas», de manera que «cualquier procedimiento de ejecución que prevean la Ley Orgánica del Tribunal Constitucional, o las normas auxiliares de procedimiento, es meramente accesorio o complementario, y solo debería activarse como mecanismo excepcional de garantía del respeto a la autoridad de sus pronunciamientos. Cuando la pérdida de la autoridad de las sentencias constitucionales se traduce en una proliferación exacerbada de los procedimientos de ejecución, o en la adopción de medidas coercitivas que 
ejecutiva de las sentencias y resoluciones del Tribunal deriva de su auctoritas y que, por tanto, excepcional ha de ser el tener que acudir a estos mecanismos de garantía, no es menos cierto que cuando, a pesar de todo, esa fuerza se desconoce, algún medio habrá que arbitrar para mantenerla. Y, en todo caso, los magistrados del Tribunal tampoco deberían estar especialmente preocupados por si se parecen en exceso a los demás tribunales de la jurisdicción ordinaria $^{14}$. Siendo distintos en muchas cosas, ninguna razón suficiente existe para que tengan que serlo en los medios puestos a su alcance para hacer cumplir lo juzgado.

\section{LAS NUEVAS FACULTADES DE EJECUCIÓN, INCLUIDA LA MULTA COERCITIVA, Y EL PRINCIPIO DE LEGALIDAD PENAL}

Entrando ya en el examen de los motivos de inconstitucionalidad específicos alegados frente a la facultad de suspensión en sus funciones de las autoridades y empleados públicos de la Administración responsable del incumplimiento, así como respecto de la que permite al Tribunal adoptar medidas de ejecución sustitutoria, hay que recordar que el primero de ellos es común al que también se esgrimiera por la Generalidad de Cataluña en su recurso dirigido contra la facultad de imponer multas coercitivas. Se trata, en concreto, de la vulneración del principio de legalidad penal.

La cuestión gira sobre la naturaleza misma de estas medidas y su posible carácter punitivo, por lo que, en tal caso, habría que dar entrada a las exigencias del principio de legalidad penal. Pues bien, la respuesta del Tribunal Constitucional me parece convincente y adecuada, apoyada en el criterio de la función o finalidad perseguida con la correspondiente medida. Se trata de un criterio finalista que, firmemente asentado en la doctrina y en el propio derecho comparado, no encuentra alternativa que se le oponga.

se acercan más a los pronunciamientos que debe adoptar la jurisdicción ordinaria, es necesario recordar esta función esencialmente declarativa de la jurisdicción constitucional».

14 Se manifiesta esa preocupación en el mismo voto particular concurrente a los AATC 126 y 127/2017: «Descender a la utilización de tales instrumentos de ejecución acerca en exceso nuestra jurisdicción a la jurisdicción ordinaria, haciéndonos perder parte de nuestra propia esencia, al tiempo que busca con tales instrumentos resolver conflictos de base política, siendo evidente la falta de adecuación de tales instrumentos al objetivo perseguido mediante el recurso a los mismos: el aseguramiento del respeto al texto constitucional». 
La STC 215/2016, de 15 de diciembre, afirma, como punto de partida, en el FJ 8, que «las garantías que la Constitución prevé para los actos de contenido punitivo no resultan sin más exigibles, de acuerdo con una reiterada doctrina constitucional, a los actos restrictivos de derechos». Añade seguidamente, de acuerdo con lo ya dicho en la STC 185/2016, de 3 de noviembre, que "para determinar si una consecuencia jurídica tiene o no carácter punitivo habrá que atender, ante todo, a la función que tiene encomendada en el sistema jurídico», y de ahí que «si tiene una función represiva y con ella se restringen derechos como consecuencia de un ilícito, habremos de entender que se trata de una pena o sanción en sentido material, pero si en lugar de la represión concurren otras finalidades justificativas deberá descartarse la existencia de una pena, por más que se trate de una consecuencia gravosa». Y a partir de estas premisas, aunque se admite que «algunos rasgos externos de las multas coercitivas pudieran conferirles cierta apariencia sancionadora» ya que, «en la medida en que consisten en la imposición de una obligación de pago a la persona responsable del incumplimiento de la resolución del Tribunal, inciden negativamente sobre su patrimonio, de forma que, al igual que las sanciones pecuniarias, aquella medida se puede traducir en la restricción de un derecho», de inmediato se puntualiza que cuando la finalidad de la medida es la de constreñir a la «realización de una prestación o al cumplimiento de una obligación concreta» y no cumple, por tanto, una función retributiva, la medida no puede ser conceptuada como sanción, tal como, por lo demás recuerda el TC_, ya se ha dicho respecto de las multas coercitivas en el ámbito administrativo (STC 239/1988, FJ 2).

De este modo, la conclusión a la que se llega es que la finalidad y funcionalidad de las multas coercitivas previstas en el art. 92.4 a) LOTC obedecen a una "función coercitiva, disuasoria o de estímulo respecto a la obligación de todos los ciudadanos y poderes públicos de cumplir las resoluciones del Tribunal Constitucional (arts. 9.1 CE y 87.1 LOTC), tendente a la modificación del comportamiento de quien incumple una resolución del Tribunal Constitucional, estando obligado a su cumplimiento», por lo que «no se trata de una medida sancionadora en sentido propio». Y excluido el carácter punitivo o sancionador de las multas coercitivas del art. 92.4 a) LOTC, queda desestimada la denunciada infracción del art. $25 \mathrm{CE}$, en la que queda subsumida, por lo demás, la del art. 9.3 CE.

Aunque no deje de ser una obviedad, aún se añade que el hecho de que la imposición de multas coercitivas no sea susceptible de impugnación o revisión ante otro órgano jurisdiccional interno «no es sino una consecuencia del modelo de jurisdicción constitucional diseñado por el constituyente, que ha configurado al Tribunal Constitucional como único en su orden» y en cuya 
virtud «las resoluciones que dicte el Tribunal Constitucional en el ejercicio de su jurisdicción son irrevisables por cualquier órgano jurisdiccional del Estado (arts. 164.1 CE y 4.1 y 93 LOTC; STC 133/2013, de 2 de julio, f.j. 6)».

Por último, en cuanto a si la horquilla de las cuantías fijada para las multas coercitivas en el art. 92.4 a) LOTC resulta desproporcionada en relación con la capacidad económica de los sujetos que pueden ser multados, se recuerda que el principio de proporcionalidad «no constituye en nuestro ordenamiento un canon de constitucionalidad autónomo, cuya alegación pueda producirse de forma aislada respecto de otros preceptos constitucionales», razón por la cual, dado que en el recurso «no se anuda a la denunciada desproporción de la horquilla de las cuantías de las multas coercitivas la infracción de precepto constitucional alguno, de manera que su existencia se alega de forma autónoma y aislada, pretendiéndose de este Tribunal un análisis abstracto del precepto impugnado», la sentencia procede sin más a la desestimación del recurso. En todo caso, no se deja de precisar que «será con ocasión de que el Tribunal decida imponer, de acuerdo con las previsiones legales, multas coercitivas a quien o quienes incumplan sus resoluciones, cuando habrá de determinarse, en atención a las particulares circunstancias que concurran en cada caso, el concreto importe de las multas, que, como es obvio, habrá de respetar el principio de proporcionalidad».

A mi juicio, la respuesta de la sentencia no admite objeción alguna. No estará de más recordar que en la doctrina se viene manteniendo de manera generalizada que las multas coercitivas no tienen carácter sancionador y, por tanto, no les alcanzan las exigencias del art. 25.1 CE. Su función es exclusivamente "disuasoria o de estímulo y no represiva», concibiéndose como un medio de ejecución forzosa de lo decidido administrativa o judicialmente. Baste señalar que la multa coercitiva constituye una técnica habitual para la ejecución forzosa de ciertas resoluciones judiciales ${ }^{15}$ y que la LEC de 2000

15 En el derecho comparado, tal como recuerda Huergo Lora (2007: 269 ss.), también se prevén estas multas coercitivas. En el derecho alemán (a diferencia del derecho francés, en el que, tras la Revolución, fueran suprimidas, si bien en las últimas reformas del contencioso-administrativo francés se han introducido), entre los medios de ejecución forzosa de las resoluciones judiciales está prevista la multa coercitiva (Zwangsgeld, en traducción literal «dinero de coacción»), que incluso puede dar lugar, en caso de impago, a la prisión por incumplimiento (Zwangshaft) (con duración de un día a dos semanas; y solo entra en juego ante el incumplimiento de la multa coercitiva). Y esta forma de privación de libertad está admitida expresamente en el Convenio Europeo de Derecho Humanos (art. 5.1.b): en efecto, junto a la privación de libertad con finalidad sancionadora, el citado precepto menciona, entre los 
también ha terminado por preverla ${ }^{16}$. Y, asimismo, la multa coercitiva es también un medio de ejecución forzosa de los actos administrativos, como consecuencia del poder de autotutela ejecutiva que a la Administración le reconoce el ordenamiento jurídico, tal como explicó la STC 239/1988, de 14 de diciembre, FJ 2.

Por lo demás, es verdad que determinados recargos tributarios se han considerado por la propia jurisprudencia constitucional sanciones (SSTC 276/2000, de 16 de noviembre, y 291/2000, de 30 de noviembre, para recargos tributarios del $50 \%$ y del $100 \%$, respectivamente), pero baste decir que tales recargos no son medios estrictos de compulsión al cumplimiento de la correspondiente obligación tributaria, sin perjuicio de que, como es obvio, en última instancia la mera previsión de toda medida punitiva pueda «estimular» al cumplimiento de la correspondiente obligación ${ }^{17}$.

supuestos en los que es lícita la privación del derecho a la libertad y a la seguridad reconocido en el art. 5 del Convenio, el siguiente: «Si [el ciudadano] ha sido detenido preventivamente o internado, conforme a derecho, por desobediencia a una orden judicial o para asegurar el cumplimiento de una obligación establecida por la ley». No obstante, en el caso Jamil contra Francia, de 8 de junio de 1995, A 317-B, el TEDH consideró que una medida muy similar a las multas coercitivas, prevista en el derecho francés para el impago de obligaciones económicas frente al Estado, que consiste en arrestar al deudor para compelerle al pago, y sin que tal arresto sustituya al pago de la obligación, es una sanción penal en el sentido del art. 7.

16 Es verdad que la LEC de 1881 no incluyó a las multas coercitivas entre los medios al alcance de la autoridad judicial para obtener el cumplimiento de las sentencias, aunque ello se debiera a la consideración de que, en los supuestos en que estas entran en juego, que son los casos de condena a un hacer personalísimo o a un no hacer, el condenado que incumplía la condena optaba por el resarcimiento de perjuicios (arts. 924 y 925). Sin embargo, la nueva LEC de 2000 ha eliminado esa facultad de opción entre el cumplimiento in natura y la indemnización, de modo que la condena solo se transforma en indemnización si lo pide el ejecutante (art. 709.1), si la ejecución in natura fuera ya imposible (art. 710.2) o si el condenado siguiere sin cumplir tras un año de multas coercitivas (art. 709.3), lo que ha dado paso a la introducción de la multa coercitiva. La exposición de motivos de la Ley lo señala claramente: «Esta Ley introduce los requerimientos y multas coercitivas dirigidas al cumplimiento de los deberes de hacer y no hacer y se aparta así considerablemente de la inmediata inclinación a la indemnización pecuniaria manifestada en la Ley de 1881».

17 La diferencia entre sanción y medida de ejecución, aun cuando sus contenidos puedan llegar a ser los mismos, la explica debidamente Huergo Lora (2007: 273), al seńalar que la multa coercitiva «no castiga un incumplimiento ya realizado, sino que la Administración [el TC cabe decir en este caso] la anuncia previamente al particular, ofreciéndole la opción entre poner fin a su conducta incumplidora, ejecutando la 
En suma, como se ha precisado oportunamente por la doctrina, a diferencia de la sanción, que solo se impone cuando ya se ha producido la infracción, la multa coercitiva no persigue ningún castigo por la acción realizada, sino convencer al interesado - por medio de la presión que conlleva la amenaza de imponerla- para que cumpla la obligación desatendida ${ }^{18}$. Lo que no es óbice, por lo demás, para que solo pueda imponerse «en la medida en que el particular frente al que se dirige esté en condiciones de cumplir la conducta que se le exige, por lo que es imprescindible aplicarle el principio de culpabilidad y el principio de presunción de inocencia» ${ }^{19}$.

Conviene recordar, por último, que la Comisión de Venecia, en su Dictamen $827 / 2015$, de 10 de marzo de $2017^{20}$, ha considerado que «la imposición de pagos muy drásticos podría cambiar la naturaleza de los mismos, sobre todo si estos se reiteran hasta que la decisión del Tribunal Constitucional resulta ejecutada y resultan adeudados importes muy elevados» (punto 45). De manera que no parece descartarse que, atendiendo a su cuantía y siempre que se cumplan los demás criterios de la jurisprudencia del Tribunal

obligación desatendida hasta ese momento, o sufrir la multa coercitiva. Esta opción no existe en el caso de la sanción, porque cuando se impone ya se ha producido la infracción (sin perjuicio de los efectos atenuantes que puede tener el arrepentimiento espontáneo allí donde esté previsto). Puede decirse [concluye Huergo] que la advertencia de sanción existe desde el momento en que está prevista legalmente, pero no es lo mismo esa previsión genérica que el apercibimiento directo y personal previo a la infracción, que es necesario en el caso de la multa coercitiva. De ahí que ésta sea, como dice la doctrina alemana, un medio de presión, no una sanción».

18 Véase Huergo Lora (2007: 273). Recuerda, a estos efectos, que en la regulación de la LPAC de las multas coercitivas como medio de ejecución, la obligación de anunciar previamente el importe de la multa, concediendo un plazo para cumplir voluntariamente el contenido del acto y eludir el pago de la multa, se deriva del inciso "previo apercibimiento» del art. 99, y así lo exige la jurisprudencia (por ejemplo, STS de 22 septiembre de 1986, arz. 5973) y 19 de junio de 1987 (arz. 6509). Y también la LEC habla de «requerir» al ejecutado con multas mensuales (arts. 709.3 y 710.1), lo que significa que se le da la opción de cumplir voluntariamente durante el plazo que se le otorga, o verse obligado a pagar la multa. En suma, la amenaza de la multa coercitiva constituye un elemento de presión en la formación de la voluntad del particular.

19 Véase Huergo Lora (2007: 275).

20 Consejo de Europa. Comisión de Venecia. España. Dictamen sobre la Ley de 16 octubre de 2015 de reforma de la Ley Orgánica 2/1979 del Tribunal Constitucional / Aprobado por la Comisión de Venecia en su 110ª sesión plenaria (Venecia, 10-11 de marzo de 2017). Traducción realizada por la Abogacía General del Estado. (Dictamen n. 827/2015) (CDL-AD (2017)003). 
Europeo de Derechos Humanos, la multa pudiera ser considerada como «infracción penal»y, en consecuencia, quedar sujeta a las garantías de un juicio justo en los términos del art. 6 del Convenio Europeo de Derechos Humanos (puntos 48 y 49). Añade la Comisión, por otra parte, que «la dicción literal de la reforma no aclara si es la autoridad quien debe abonar la multa o [debe hacerlo] el empleado público de sus fondos personales» y que «la ley o su aplicación debería proporcionar distinto tratamiento cuando la multa se impone a autoridades públicas, funcionarios o particulares» (punto 46). E, incluso, se plantea la cuestión de «si los pagos pueden ejecutarse», razonando a tal efecto que «las medidas con arreglo al párrafo 4 del art. 92 se aplican únicamente cuando la autoridad o el particular interesado ya se han negado a acatar la resolución definitiva y vinculante del Tribunal Constitucional y el requerimiento del informe no implica su ejecución», de manera que "la cuestión es por qué una autoridad, que ya ha vulnerado la Constitución negándose a ejecutar una resolución definitiva y vinculante de la Constitución, acataría otra resolución del Tribunal Constitucional imponiendo una multa», pues «es posible que dicha autoridad no respetase tampoco dicha medida» (puntos 50 y 51). Todo lo cual, ante el riesgo de que la «falta de respeto flagrante y reiterado de las resoluciones del Tribunal Constitucional pueden socavar gravemente su autoridad y, a su vez, la Constitución», hace aconsejable que «una vez que el Tribunal Constitucional ha dictado una resolución y existe la negativa a implementarla, deberían intervenir otros organismos para defender la Constitución y el Tribunal Constitucional» (punto 52).

Ahora bien, todas estas apreciaciones de la Comisión de Venecia no dejan de suscitar serias reservas si se examinan desde la lógica de un mínimo rigor jurídico. Baste decir, sin entrar ahora en mayores detalles, que las multas coercitivas - al menos así sucede en el ámbito de la jurisdicción contencioso-administrativa, y nada determina que no deba serlo en el ámbito de la justicia constitucional - solo pueden imponerse con cargo al patrimonio privado de las personas físicas integrantes de la Administración condenada - es decir, autoridades y funcionarios- y no a esta misma como persona jurídica ${ }^{21}$. La propia finalidad de la multa coercitiva determina, en efecto, que deberá asumirla la persona física a quien se pueda imputar el incumplimiento, siempre, claro es, que quede acreditada su responsabilidad, comprobando que su conducta es la determinante de la inejecución de la sentencia. Por otra parte, la hipótesis de que una cuantía desproporcionada pudiera justificar la calificación

21 Como ha puntualizado Santamaría Pastor (2010: 1168), es ilegítimo que la Administración personificada asuma el abono de dichas multas, haciéndoles perder su función coactiva. 
de la multa coercitiva como sanción tampoco presenta mayor fundamento, aunque solo lo sea porque para rechazar la viabilidad jurídica de una multa desproporcionada no es preciso transformar su naturaleza jurídica. Basta simplemente con constatar que infringe el principio de proporcionalidad. Y en cuanto al riesgo de que la autoridad del TC quede menoscabada si la ejecución de la multa coercitiva impuesta no se puede hacer efectiva, tampoco pasa de ser una objeción sustentada en el desconocimiento de que los concretos medios previstos por el ordenamiento jurídico impiden que un supuesto tal pueda hacerse realidad. Como de inmediato recordaré, en la primera y hasta ahora única ocasión en la que el TC ha recurrido a su utilización, la efectividad de la multa coercitiva ha sido plena y absoluta.

En efecto, tras la reforma de 2015, el TC ha hecho uso de este medio de compulsión, quedando plenamente acreditada su eficacia. El ATC 127/2017, de 21 de septiembre, acordó imponer multa coercitiva, con periodicidad diaria (siendo días naturales) de 12000 euros, al secretario general de la Vicepresidencia y de Economía y Hacienda de la Generalitat de Cataluña, y de 6000 euros a la jefa del área de procesos electorales y consultas populares, en tanto no procediesen a justificar ante el Tribunal que han «revocado cualquier resolución que hayan dictado para la preparación, ejecución y/o promoción del referéndum ilegal catalán», "clausurado el contenido de [determinada] página oficial y cualquier otra destinada al mismo fin, así como cualquier otro instrumento de difusión del referéndum en las redes sociales», "acordado el cese de toda colaboración en la campaña institucional del referido referéndum», y «notificadas a todas las personas afectadas las revocaciones y suspensiones que acuerden», y todo ello «sin perjuicio de que este Tribunal pueda realizar una valoración final de la entidad del eventual incumplimiento y de su persistencia, con carácter individualizado». Y conviene recordar que, asimismo, se acordó «comunicar este auto al Presidente de la Agencia Estatal de la Administración Tributaria para que proceda, incluso por la vía de apremio, si fuere necesario, al cobro de las multas referidas, a cuyo efecto este Tribunal le dirigirá el oportuno oficio fijando las cantidades que por este concepto se hubieran devengado». Por lo demás, lo mismo se había acordado por ATC 126/2017, de 20 de septiembre, en relación con las personas designadas miembros de la sindicatura electoral de Cataluña y de las correspondientes demarcaciones electorales (12000 euros para los primeros y 6000 para los segundos) ${ }^{22}$.

2 Los referidos Autos se dictaron como consecuencia de la solicitud del abogado del Estado de que se impusieran multas coercitivas —en la cuantía que el Tribunal estimase conveniente- a la vista de las actuaciones realizadas por los miembros de las sindicaturas y a fin de vencer la persistencia en el incumplimiento de las resoluciones 
Pues bien, la multa adoptada surtió plenos efectos. Por providencia del Pleno del Tribunal de 26 de septiembre siguiente (el Auto se publicó en el BOE de 22 de septiembre y el plazo para cumplir se fijó a las $10 \mathrm{~h}$. de la mañana del día siguiente, es decir, el día 23), se hizo público el «escrito de renuncia» de los afectados a los cargos para los que fueron designados presentado ante el Tribunal Constitucional, en el que, además, manifestaron haber «dejado previamente sin efecto las resoluciones y acuerdos adoptados» $\mathrm{y}$, en su caso, que «no se ha adoptado ninguna resolución ni acuerdo a excepción de la propia constitución de la sindicatura de demarcación que queda sin efecto». El efecto disuasorio consustancial a la multa coercitiva mostró así toda su potencialidad, a pesar de que los tres magistrados que formularon voto particular concurrente a los Autos habían afirmado que «a nuestro juicio, existen algunos motivos para dudar de la efectividad de esta medida», pues "este medio de ejecución forzosa [la multa coercitiva] se utiliza para obligar a hacer algo, no

del Tribunal y hasta el cumplimiento íntegro de lo acordado. El TC, tras reiterar que con estas multas «no [se] pretende reprender o sancionar el incumplimiento de las resoluciones de este Tribunal, [sino] el obtener la acomodación de un comportamiento que desconoce una resolución del Tribunal», recuerda cuáles son los presupuestos para imponerlas (la existencia de un título ejecutivo, el conocimiento claro y terminante por parte de quien ha de cumplir, disponiendo para ello de tiempo suficiente, y la resistencia o comportamiento obstativo a cumplir), así como el que «la medida habrá de reputarse inidónea o inadecuada si entorpece o, incluso, si resulta indiferente en punto a la satisfacción de su finalidad», de manera que «la multa coercitiva impuesta no puede ir más allá de lo estrictamente necesario para lograr su propósito" y el mismo principio de proporcionalidad debe proyectarse sobre la cuantía y sobre los plazos iniciales y sucesivos para ejecutar la obligación incumplida. De este modo, tras un relato pormenorizado de los hechos, los Autos concluyen que «sin perjuicio de la eventual existencia de indicios racionales de responsabilidad penal», concurren los presupuestos para imponer las respectivas multas coercitivas solicitadas. Y las impone fijando la cuantía y plazo concedido para que los obligados cumplan, a efectos de evitar que la multa se haga efectiva.

Por otra parte, el Tribunal hace uso de la facultad prevista por el art. 92.5 LOTC y las impone inaudita parte, sin oír a los obligados, "al concurrir circunstancias de especial trascendencia constitucional», puntualizando que "tales circunstancias se concretan en la existencia de un "supuesto de incumplimiento notorio", al que alude el preámbulo de la Ley Orgánica 15/2015 como ejemplo de supuesto de especial trascendencia constitucional, así como por la gravedad y carácter inminente de los perjuicios que pueden ocasionarse tanto al orden político como a la paz social, al socavar las normas y resoluciones suspendidas, la soberanía nacional y la Constitución misma» (f. j. 8). 
para garantizar que no se haga $»^{23}$. Sin embargo, la multa coercitiva logró que quienes se disponían a hacer lo que previamente había resuelto el Tribunal que no se podía hacer, desistieran fulminantemente de hacerlo.

\section{LA SUSPENSIÓN DE AUTORIDADES O EMPLEADOS PÚBLICOS}

Por lo que respecta más específicamente a la «suspensión en sus funciones de las autoridades o empleados públicos de la Administración responsable del incumplimiento, durante el tiempo preciso para asegurar la observancia de los pronunciamientos del Tribunal» [art. 92.4.b)], resuelto el tema de la compatibilidad de esta medida desde la consideración del principio de legalidad penal del art. $25 \mathrm{CE}$ en razón de la finalidad y función no punitiva de la misma, y sin perjuicio de las precisiones y criterios que acerca de su concreto ejercicio se enuncian en las SSTC 185 y 215/2016 — sin que, por ello, sea objetable que las mismas no se hayan configurado como sentencias interpretativas, lo que también se reprocha en uno de los votos ${ }^{24}$-, me limitaré a hacer las siguientes precisiones.

Que la suspensión, obviamente, no siendo en este caso medida cautelar, sino un medio de ejecución, puede ser medida idónea o apropiada para hacer efectivo el cumplimiento de la correspondiente resolución, por cuanto esta puede determinar una obligación de hacer pero también una obligación de no hacer, es decir, la obligación de abstenerse de realizar determinadas acciones. $\mathrm{Y}$ es precisamente respecto de este supuesto cuando la suspensión en las

23 Se trata del voto concurrente de los magistrados Valdés y Xiol y de la magistrada Balaguer, ya citado.

24 Concretamente en el voto de la magistrado Asúa. Considera que las condiciones que la propia sentencia fija para que las medidas previstas en las letras b) y c) del arts. 92.4 LOTC puedan ser adoptadas «no están contempladas en el propio precepto legal impugnado, ni se infieren de una interpretación sistemática», por lo que "la única vía para que el Tribunal Constitucional hubiera impuesto esas condiciones interpretativas tendría que haber sido la técnica de la interpretación conforme, cuyo presupuesto lógico es, precisamente, la previa constatación de una contradicción directa y frontal entre, al menos, parte del enunciado legal y la Constitución». Y de ahí que mantenga que la sentencia lleva a cabo "una interpretación conforme "disimulada", que no se identifica como tal, ni se lleva al fallo». Sin embargo, la objeción, como fácilmente se ve, es de carácter más formal que sustancial y, en todo caso, de muy escasa entidad, pues las sentencias no hacen otra cosa que recordar que corresponde al propio Tribunal hacer aplicación de esas medidas y anticipar, además, que lo hará con arreglo a determinadas condiciones. 
funciones de quién teniendo que abstenerse de hacer no se abstiene, puede desplegar toda su eficacia.

Ciertamente, «quien resulta ser suspendido en el cargo que ocupa deja de estar en situación de cumplir con las obligaciones derivadas de su cargo", de lo que se ha tratado de deducir que, consecuentemente, «el sentido de la suspensión de funciones no reside en la imposición del cumplimiento de obligaciones derivadas de resoluciones jurisdiccionales, sino en la finalidad represiva, retributiva o de castigo que caracteriza a las medidas sancionadoras por negarse a cumplir o no facilitar un determinado cumplimiento ${ }^{25}$. Sin embargo, parece

25 Así en los votos particulares de la magistrada Asúa y del magistrado Xiol. Dice la primera: "Quien resulta ser suspendido en el cargo que ocupa deja de estar en situación de cumplir con las obligaciones derivadas de su cargo, tampoco, por tanto, de cumplir el pronunciamiento contenido en el fallo de una resolución del Tribunal Constitucional. Por eso, el sentido de la suspensión de funciones no reside aquí en la imposición del cumplimiento de obligaciones derivadas de resoluciones jurisdiccionales, sino en la "finalidad represiva, retributiva o de castigo" que caracteriza a las medidas sancionadoras (por todas, STC 164/1995, de 13 de noviembre, f.j. 4) por negarse a cumplir o no facilitar un determinado cumplimiento». Y más adelante: «Si la persona responsable del incumplimiento está suspendida en sus funciones, ya no puede realizar la actividad requerida para dar cumplimiento al pronunciamiento del Tribunal Constitucional, con independencia de que en un momento posterior cese su voluntad incumplidora", de lo que concluye que «el art. 92.4 b) LOTC atribuye al Tribunal Constitucional facultades de carácter materialmente sancionador con respecto a autoridades y empleados públicos por el incumplimiento de las resoluciones de dicho Tribunal».

Por su parte, el magistrado Xiol parece no concebir que la medida de suspensión se pueda vincular al cumplimiento de una obligación de no hacer, al razonar en estos términos: «La opinión mayoritaria en la que se sustenta la sentencia afirma que "es una medida que habrá de levantarse tan pronto como cese la voluntad incumplidora de la autoridad o empleado público responsable del cumplimiento de la resolución”. Pero la referencia explícita al cese de la voluntad incumplidora de la autoridad o empleado público como uno de los criterios para el levantamiento de la medida pone de manifiesto que para esta opinión mayoritaria la finalidad de esta medida de suspensión puede no ser exclusivamente la de remover un obstáculo para la ejecución de la resolución incumplida a través de la suspensión puntual de la autoridad o empleado público incumplidor mediante su sustitución por otro que posibilite la ejecución de la resolución constitucional, sino conseguir doblegar la voluntad incumplidora. Ese objetivo, nuevamente, redunda en aspectos que la alejan de una pura medida de ejecución y la acercan a medidas sancionatorias en que lo relevante no es garantizar la ejecución de la resolución incumplida, sino la de adoptar una consecuencia jurídica en represión por una conducta renuente al cumplimiento de la resolución. Además, vendría a permitir, profundizando también en su carácter represivo, que esa medida 
olvidarse que cuando la obligación derivada de la resolución consiste en no hacer, justamente la suspensión en su función de la autoridad o empleado que hace lo que no debe hacer puede garantizar el efectivo cumplimiento de lo decidido. Carece, pues, de toda lógica el argumento empleado y, en todo caso, corresponderá al Tribunal, a la luz del supuesto que pueda plantearse, determinar la idoneidad o no de recurrir a esta concreta medida.

No deja de ser llamativo, por otro lado, que, entre las consideraciones acerca de la constitucionalidad o no de la medida de suspensión de funciones, cuando la misma pudiera alcanzar a cargo elegido por sufragio universal, quedando así afectado el derecho fundamental que reconoce el art. $23 \mathrm{CE}$, no se haya hecho ninguna precisión acerca de la literalidad misma del art. 92.4.b). Recuerdo cuál es: «Acordar la suspensión en sus funciones de las autoridades o empleados públicos de la Administración responsable del incumplimiento». ¿Queda ceñida, pues, la suspensión a quienes sean autoridades administrativas o, a pesar de la referencia expresa a la Administración responsable del incumplimiento, se debe entender que también están incluidos los cargos elegidos por sufragio? La redacción puede suscitar la duda, aunque seguramente carezca de justificación. Y ello porque ni en las sentencias, ni en los votos particulares, se alude a este extremo y no dejaría de ser sorprendente que, de existir el más mínimo fundamento para sustentarla, la misma hubiera pasado desapercibida, sin merecer al menos alguna consideración.

de suspensión se torne en temporalmente ilimitada al vincularse no a que se haya ejecutado definitivamente la resolución incumplida, sino a la necesidad de que la autoridad o empelado público cese en su voluntad incumplidora. En última instancia, la opinión mayoritaria en la que se sustenta la sentencia viene a posibilitar que esta medida se adopte como un mecanismo para doblegar la voluntad de la autoridad o empleado público incumplidor mediante la suspensión en sus funciones». Y la misma idea de que, en todo caso, la aplicación de esta medida de suspensión solo podría justificarse cuando el incumplimiento recayera «en una obligación de hacer», de manera que viniera «a posibilitar que su sustituto pudiera adoptar las decisiones necesarias para la ejecución de la resolución judicial que estuviera siendo incumplida», aparece expresamente formulada al afirmar que, incluso en ese caso, «el recurso a la suspensión de funciones como medidas de ejecución resulta desproporcionado", ya que «aun limitando esta medida a las obligaciones de hacer, la capacidad de ejecución de este Tribunal frente a su incumplimiento podría quedar siempre garantizada con la posibilidad de dictar una resolución jurisdiccional con carácter ejecutivo [...]». Todo lo cual le lleva a concluir que la medida controvertida «es innecesaria y desproporcionada en cuanto a su mera función de medida de ejecución y que, por tanto, siempre hace emerger de manera permanente un componente sancionador subyacente del que es difícil que se desprenda». 
Con todo, aun cuando se dé por supuesto que la medida puede alcanzar a los cargos parlamentarios y representativos protegidos por el derecho fundamental del art. 23.1 de la Constitución, me sumo a la opinión de Ignacio Díez-Picazo (2017), que ya ha dicho que la suspensión, también en esos casos, tiene un fundamento objetivo y razonable, pues «ni los interna corporis ni la elección por sufragio universal pueden oponerse al cumplimiento de las resoluciones del Tribunal Constitucional. Lo contrario sería tanto como negar al Tribunal su jurisdicción. Y la proporcionalidad en abstracto de la medida de suspensión no puede ser negada».

Por último, frente al hecho de que en nuestro ordenamiento no conozca supuestos de suspensión que no vayan conectados a procedimientos sancionadores $^{26}$, no me parece que la objeción tenga mayor alcance ${ }^{27}$. Más aún, puestos a hilar fino, hasta sería discutible que materialmente no exista ya, de facto, la suspensión de funciones. Pues, en efecto, no otra consecuencia dimana de la utilización de medidas de ejecución subsidiaria previstas para el orden contencioso-administrativo por el art. 108.1 de la Ley de dicha jurisdicción. Lo diré ahora con palabras de Juan Alfonso Santamaría Pastor (2010: 1138): "Obsérvese que, cuando se requiere para la ejecución a otra Administración distinta a la condenada (la llamada "ejecución comisarial"), la orden del juez deja en suspenso, para el caso de autos, el sistema general de distribución de competencias: la Administración requerida realizará una actividad para la que abstractamente no es competente, pero que viene a serlo para ese caso concreto en virtud del requerimiento judicial». Así pues, dada la similitud de efectos, no resulta admisible que el juez contencioso-administrativo cuente con esta facultad sin mayor problema y, sin embargo, se haya defendido que su atribución al Tribunal Constitucional es inconstitucional.

\section{LA EJECUCIÓN SUSTITUTORIA}

Vayamos ahora a la cuestión de las medidas de ejecución sustitutoria previstas en el art. 92.4.c) LOTC. Las dos sentencias han rechazado que con esa atribución se hayan vulnerado los arts. 143 y 155 de la Constitución. El Tribunal ha considerado que la ejecución sustitutoria puede requerir la colaboración del Gobierno de la nación, colaboración que ha de desarrollarse

26 Cuestión en la que también insisten los votos particulares de la magistrada Asúa y del magistrado Xiol.

27 Puede suscribirse la castiza expresión de Díez-Picazo (2017) de que «alguna vez tenía que ser la primera». 
en los términos que fije el propio Tribunal. De manera que no es el Gobierno quien discrecionalmente decide intervenir en la ejecución sustitutoria, ni quien decide qué medidas concretas implica la ejecución, por lo que el título legitimador de esta medida de ejecución no es un supuesto título competencial del Estado, sino, como el resto de medidas previstas en el art. 92.4 LOTC, la garantía de la efectividad y cumplimiento de las resoluciones del Tribunal Constitucional.

Además, puntualiza el TC que se podrá acudir a la ejecución sustitutoria cuando pueda resultar una medida de ejecución idónea y procedente para el cumplimiento de las resoluciones del Tribunal, lo que este habrá de valorar en cada caso concreto atendiendo a las circunstancias concurrentes en el mismo. $\mathrm{Y}$, asimismo, que la aplicación de esta medida, al igual que los demás instrumentos de ejecución del art. 92.4 LOTC, habrá de cohonestarse y respetar siempre las previsiones constitucionales y nunca podrá dar lugar a la alteración de la posición institucional del Estado y de las comunidades autónomas, conforme a la Constitución y a los estatutos de autonomía, y sí solo a la circunstancial adopción de las medidas necesarias y, por tanto, proporcionadas para la ejecución del fallo.

Pues bien, la principal objeción que se ha formulado a que el Tribunal disponga de esta nueva facultad ejecutiva es que la misma viene a solaparse con las facultades coercitivas que al Gobierno de la nación le reconoce el art. 155 de la Constitución. Un solapamiento que vendría a alterar el modelo de control de las comunidades autónomas diseñado por el constituyente y que es un modelo en el que el conflicto ha de ser resuelto por instancias políticas, a través de mecanismos políticos y no jurisdiccionales. Los votos particulares de los magistrados Valdés y Xiol insisten en este planteamiento, en cuyo análisis detallado no es preciso adentrarse ${ }^{28}$.

28 Baste recordar la conclusión a la que llega el magistrado Valdés: «La ejecución sustitutoria del art. 92.4 c) LOTC nos llega revestida de una apariencia de medida de ejecución jurisdiccional de vis neutra, técnica, con el soporte como precedente de la legislación procesal ordinaria, y con ficta vocación de aséptica generalidad. Pero si la sentencia hubiera transcendido la perspectiva meramente formal, para adentrarse en un análisis material, sistemático y teleológico, hubiera sido forzoso apreciar el altísimo grado de coincidencia o solapamiento entre el núcleo real de la medida de ejecución sustitutoria del art. 92.4 c) LOTC y el poder de coerción estatal que el constituyente recogió en el art. $155 \mathrm{CE}$, que en su génesis parlamentaria quedó configurado como un control político discrecional en las solas manos del Gobierno y del Senado, al quedar descartadas las propuestas que propugnaban la intervención del Tribunal Constitucional en alguna de sus fases. Esta duplicidad, que produce la 
Diré, no obstante, que la premisa misma de la que parten dichos votos, así como algunas posiciones doctrinales, consistente en que el art. 92.4.c) LOTC tiene como finalidad sustituir a las instituciones o autoridades de las comunidades autónomas que incumplen el fallo de una resolución del Tribunal Constitucional, es la resultante de una determinada acotación subjetiva y objetiva de los supuestos en los que resulta aplicable la ejecución sustitutoria. Pero esa acotación, realizada tal como se hace en abstracto, cuando menos resulta discutible. Máxime cuando, con frecuencia, la realidad termina ilustrándonos con supuestos que ni con el mayor de los derroches de imaginación podríamos haber previsto, por lo que no deja de parecerme arriesgado concluir, tal como lo hace el magistrado Valdés, que la medida sustitutoria nunca

irrupción del Tribunal en un ámbito reservado por la Constitución a otros órganos constitucionales, es la que pone en entredicho la constitucionalidad del citado precepto de la reforma de la Ley Orgánica del Tribunal Constitucional de 2015».

Por su parte, el magistrado Xiol apostilla que «la configuración de la Ley Orgánica del Tribunal Constitucional ahora impugnada altera de manera sustancial este diseño constitucional y los equilibrios procurados por el Poder constituyente entre los distintos órganos constitucionales al enfrentar este tipo de conflictos. En primer lugar, pone en un plano de prioridad al Tribunal Constitucional, que es al que correspondería decidir sobre (i) la existencia del incumplimiento; (ii) las medidas que deben adoptarse; y (iii) requerir al Gobierno y dirigir su actuación para asegurar el debido cumplimiento de sus obligaciones constitucionales por parte de la Comunidad Autónoma incumplidora. Pero, en segundo lugar, paradójicamente, coloca también al Tribunal Constitucional en un plano de subordinación al Gobierno, habida cuenta de las posibilidades de iniciativa con que este cuenta en el marco de los procedimientos constitucionales y de sus incidentes de ejecución y de que, como ya se expuso anteriormente, son medidas que se configuran como potestades del Tribunal frente a cuyo cumplimiento no puede sustraerse ni alegar razones de oportunidad mucho menos de carácter político- para evitar su adopción. Esta reubicación del protagonismo del Tribunal Constitucional en el procedimiento de resolución de este tipo de conflictos, además, lo inhabilita, al menos en esa concreta cuestión, para ejercer una posterior labor de control de constitucionalidad sobre la forma en que se hubieran desarrollado las medidas de ejecución sustitutorias. De ese modo se altera también la función de garante que la Constitución reserva para la jurisdicción de este Tribunal Constitucional y, en suma, desdibuja gravemente su papel como órgano constitucional de garantía. Un panorama como el expuesto debería haber llevado a la conclusión de que la mutación que en el diseño originario constitucional supone la norma controvertida era determinante de su inconstitucionalidad no solo por otorgar al Tribunal Constitucional funciones que exceden de las que constitucionalmente tiene reconocidas, sino porque, además, desapodera de ellas a otro poder constituido como es el Gobierno, que sí las tiene constitucionalmente reconocidas». 
podrá alcanzar a los particulares, ni a la Administración local, ni nunca será necesaria en relación con resoluciones dictadas en procesos de inconstitucionalidad, ni en conflictos de competencia, ni siquiera en amparos.

Ciertamente, por la propia causa desencadenante de la reforma, la previsión de esta medida de ejecución sustitutoria ha estado presidida por la intencionalidad de que la acción del Tribunal Constitucional sea un medio complementario de reacción frente a los incumplimientos de la Comunidad Autónoma de Cataluña. Un medio de reacción a cargo del Tribunal que bien pudiera hacer innecesaria la reacción del Gobierno de la nación. Pero, aun cuando así sea, no me parece que ello permita concluir que dicha atribución sea inconstitucional.

En todo caso, el solapamiento no puede decirse que sea pleno atendiendo a la causa o presupuesto determinante de la activación de una medida sustitutoria o de la adopción de las medidas a las que puede dar cobertura el famoso art. 155 de la Constitución, ni tampoco puede decirse con absoluta seguridad que solo por relación a incumplimientos de las comunidades autónomas pueda ser aplicable la medida sustitutoria. Y, asimismo, no debe silenciarse que la jurisdicción contencioso-administrativa tiene atribuida esta facultad de ejecución, que en la LJCA se denomina subsidiaria, y que la misma, pudiendo alcanzar a cualesquiera Administraciones públicas, incluidas las autonómicas, nunca ha suscitado duda alguna de constitucionalidad por un posible solapamiento con el art. 155 de la Constitución.

Por otra parte $-y$ es evidencia que corrobora cuál ha sido la finalidad perseguida—, el art. 92.4.c) únicamente prevé la posibilidad de requerir la colaboración del Gobierno de la nación. Pero, como la propia STC 215/2016 ha precisado, ello no impide que el Tribunal, en su caso, pueda requerir la colaboración de otros órganos o Administraciones públicas al amparo de lo dispuesto por el art. 92.2 LOTC, que le faculta para «recabar el auxilio de cualquiera de las administraciones y poderes públicos para garantizar la efectividad de sus resoluciones». En suma, que la mención al Gobierno de la nación no es excluyente de la posibilidad de que el Tribunal pueda requerir, si lo considera preciso, la colaboración de cualesquiera otros poderes.

\section{LA ADOPCIÓN DE LAS MEDIDAS INAUDITA PARTE}

Finalmente, la posibilidad de que se adopte inaudita parte la correspondiente medida tendente a garantizar el cumplimiento de la suspensión de la disposición, acto o actuación, queda ceñida a los supuestos de suspensión automática del art. 161.2 CE y no a los demás supuestos de suspensión que el Tribunal puede acordar. 
Pues bien, se trata de una medida complementaria absolutamente razonable. Es lógico que el aseguramiento de la observancia de la medida cautelar de suspensión de que se trata venga acompañado, por la singularidad misma de tal suspensión, de la posibilidad de que la medida ejecutiva pueda adoptarse de inmediato, sin necesidad de formular requerimiento y con un régimen de audiencia diferida cuando se aprecien circunstancias de especial trascendencia constitucional. La cuestión, por tanto, no me parece que suscite mayores problemas.

Por lo demás, la determinación de cuáles son esas circunstancias de «especial trascendencia constitucional» corresponde realizarla en exclusiva al Tribunal a la luz de los supuestos concretos que puedan plantearse, aunque siempre dentro de un amplio margen de apreciación ${ }^{29}$.

\section{OTRAS NOVEDADES}

Quedan por hacer algunas precisiones acerca de las demás novedades, de menor importancia o secundarias, que incorpora la reforma. Me refiero a la regla de la supletoriedad de la LJCA, a las notificaciones personales y requerimientos y a la condición de título ejecutivo de las resoluciones del Tribunal. En cuanto a la deducción de testimonio de particulares a los efectos de posible responsabilidad penal, aunque formalmente no figuraba en la redacción de la LOTC anterior a la reforma, el propio Tribunal ha declarado que siempre ha estado a su alcance ${ }^{30}$.

29 Así lo ha hecho en los ATC 126 y 127/2017, con ocasión de imponer multas coercitivas.

30 Véase ATC 170/2016, de 6 de octubre, FJ 2: «La expresa referencia en las actuales letras [...] d) del art. 92.4 LOTC, en la redacción de la Ley Orgánica 15/2015, [...] a la deducción de testimonio de particulares para exigir la responsabilidad penal que pudiera corresponder, como medida ejecutiva que este Tribunal puede aplicar si aprecia el incumplimiento de sus resoluciones, no supone atribución a este Tribunal de facultades de las que no dispusiera ya desde su entrada en funcionamiento. Este Tribunal ha contado siempre con tales atribuciones, con independencia de que no se haya encontrado hasta la fecha en la necesidad de recurrir a ellas para asegurar el cumplimiento de sus resoluciones». Por lo demás, también se prevé en la LJCA, pero de ese traslado se hace poco uso ya que, según Santamaría Pastor (2010: 1170-1171), la tipificación del delito de desobediencia hace que sea prácticamente imposible su comisión. Y es que el art. 410 del Código Penal tipifica como tal delito la negación «abierta» de la autoridad/funcionario a dar el debido cumplimiento a las resoluciones judiciales dictadas dentro del ámbito de su respectiva competencia y revestidas de las 
En primer lugar, la LJCA pasa a ser de aplicación supletoria en relación con la ejecución, tal como resulta del nuevo párrafo añadido al art. 80 LOTC $^{31}$. Se trata de un añadido técnicamente discutible, aunque también de muy escasa significación. Díez- Picazo (2017) ha señalado que establecer sin más que la LJCA es supletoria de la LOTC en materia de ejecución no es adecuado si no se hacen distingos, ya que dicha supletoriedad no tiene sentido en amparos que tengan su origen en el orden civil, penal o social. Y por ello mismo considera que no cabe excluir la aplicación supletoria de otras normas procesales, todo ello sin perjuicio de que «teniendo en cuenta lo que innova el artículo 92 LOTC, como potestades del TC, resulta difícil encontrar muchos supuestos de aplicación supletoria de la LJCA. Una vez regulado lo que se ha regulado en el artículo 92 LJCA, no se acaba de ver qué ámbito real y práctico tendrá la supletoriedad de la LJCA $»^{32}$.

Ahora bien, no puede olvidarse que la propia LJCA da entrada a la aplicación supletoria de la LEC (disposición final primera), con lo que, al menos en parte, el inconveniente queda paliado. Y, asimismo, también conviene tener en cuenta que la expresa llamada de la LOTC a la aplicación supletoria de la LJCA, aunque pudiera dar pie, por ejemplo, a que el órgano obligado al cumplimiento de la resolución plantease la imposibilidad material o legal de proceder a su ejecución atendiendo a los términos y condiciones que prevé el artículo 105.2 LJCA, en realidad poco nuevo añade, ya que el TC siempre ha podido modular, y en no pocas ocasiones modula, los efectos de sus senten$\operatorname{cias}^{33}$. De esta forma, implícitamente al menos, se anticipa el resultado al que,

legalidades formales. Pero es que, además, la jurisprudencia mantiene una interpretación restrictiva, pues, no solo exige que la desobediencia sea «negativa franca, clara, patente, indudable, indisimulada, evidente o inequívoca», sino que requiere un dolo específico, una voluntad deliberada de incumplir los mandatos judiciales, con lo que queda excluida la comisión culposa, por error o mala inteligencia de su contenido y alcance. En consecuencia, concluye el referido autor que «ante esta doctrina, sólo cabe decir, con toda claridad, que es preciso ser muy ignorante o tener seriamente disminuidas las facultades mentales para que una autoridad incurra en este delito. Las desobediencias abiertas, flagrantes y chulescas a los mandatos judiciales de ejecución no existen en la actualidad». No obstante, como en tantas ocasiones sucede, la realidad ha venido a desmentir tan razonables apreciaciones, al menos en el ámbito de la justicia constitucional.

31 Dice así: «En materia de ejecución de resoluciones se aplicará, con carácter supletorio de la presente Ley, los preceptos de la Ley de la Jurisdicción Contencioso-administrativa».

32 Sin embargo, la considera totalmente acertada Villaverde Menéndez (2017: 645).

33 Caso, por ejemplo, de las sentencias que declarando la inconstitucionalidad de la ley, disposición o acto impugnado, a dichas declaraciones no vinculan necesariamente 
en otro caso, podría llegarse a través de un incidente de ejecución en el que, con el significado señalado, se constatase la imposibilidad material de la ejecución.

En segundo lugar, la facultad de que «en particular, el Tribunal Constitucional podrá acordar la notificación personal de sus resoluciones a cualquier autoridad o empleado público que se considere necesario» (art. 87.1, párr. 2º), no pasa de ser una facultad meramente instrumental $y$, a la vez, consustancial e inherente a la función de hacer ejecutar lo juzgado, por lo que puede considerarse que el TC ya disponía de la misma. Como ha puntualizado una vez más Díez-Picazo (2017), esta notificación personal es facultativa, puede acordarse de oficio o a instancia de parte, no hay momento preclusivo para acordarla, puede ser dirigida a cualquier autoridad o empleado que el TC considere necesario y sin que tenga que preceder el incumplimiento de la resolución que se notifica, y en modo alguno se erige en requisito para la adopción posterior de cualesquiera de las medidas compulsivas que prevé el art. 92 LOTC. En todo caso, lo más destacable es que quien sea notificado personalmente no podrá ya alegar en ningún caso desconocimiento de su existencia y contenido, aunque no es menos cierto que, como contrapartida, la falta de notificación personal puede ahora dar más consistencia al argumento de la exoneración de una posible responsabilidad penal por incumplimiento.

Por último, se ha previsto que, a los efectos del auxilio jurisdiccional que el TC solicite a juzgados y tribunales, las «sentencias y resoluciones del Tribunal Constitucional tendrán la consideración de títulos ejecutivos» (art. 87.2). También el precepto ha sido criticado, por considerar que confunde y mezcla indebidamente ejecución e incumplimiento y sobre todo porque ningún sentido tiene decir que la resolución del TC es título ejecutivo "a estos efectos», es decir, a los efectos del auxilio judicial que le puede tener que prestar otro

los efectos ex tunc que, en principio, corresponderían. La modulación, entre otras razones, se puede deber a la constatación de que, en otro caso, el estricto y efectivo cumplimiento de la sentencia podría suponer «un coste económico y un esfuerzo absolutamente desproporcionado en relación con el beneficio que [...] puede obtener[se] de su completa ejecución». Y es que, en términos prácticos, la declaración de imposibilidad material de ejecución no pasa de ser equivalente a que la ejecución se considera «extremadamente difícil o desproporcionadamente costosa», pues, como advierte Santamaría Pastor (2010: 1108-9), «en la realidad jurídica existen muy escasas actividades que puedan considerarse como absolutamente imposibles y es insólito que las sentencias pronuncien condenas de dar, hacer o no hacer que atenten contra las leyes físicas (únicas que determinan las situaciones de auténtica imposibilidad), o que impongan conductas que sean irrealizables en el actual estado de la técnica». 
tribunal ${ }^{34}$. Con todo, tampoco se ha dejado de precisar que esa condición de título ejecutivo —además del elenco de títulos ejecutivos del art. 517.9 LEC— puede ser muy útil en relación con las sentencias estimatorias de recursos de amparo, aunque por eso mismo no es lógico que dicha condición quede limitada a los supuestos en los que el TC recabe el auxilio judicial ${ }^{35}$.

\section{CONSIDERACIÓN FINAL}

La reforma ha provocado más ruido que otra cosa. Un ruido en gran medida innecesario porque la reforma no era imprescindible, como bien lo están probando los hechos. Pero innecesario también, y sobre todo, porque ha dado pábulo a que se haya magnificado su trascendencia y relevancia constitucional, llegándose a mantener que la misma afecta frontalmente a la naturaleza, posición y funciones del Tribunal Constitucional y a los equilibrios de los poderes del Estado y que, incluso, supone una suplantación del poder constituyente por el legislador orgánico y, por tanto, una mutación del diseño originario constitucional, y no solo por otorgar al Tribunal Constitucional funciones que exceden de las que constitucionalmente tiene reconocidas, sino porque, además, desapodera de ellas a otros poderes, como es el Gobierno. Sin embargo, como ya he dicho, son afirmaciones notoriamente excesivas, incluso alarmistas, que no han tenido otra virtualidad que proyectar injustificadas sombras y dudas que en nada favorecen a la posición institucional del Tribunal.

En todo caso, en el supuesto de que pudiera llegarse a plantear la necesidad de hacer uso de las facultades de suspensión o de ejecución sustitutoria, que son las que mayor oposición han levantado, lo relevante es que será el Tribunal quién decidirá con un amplio margen de apreciación, correspondiéndole valorar la constitucionalidad misma de acceder o no a la aplicación de la concreta medida de que se trate y la determinación de las condiciones en que se habrá de aplicar. Téngase en cuenta, a este respecto, que cada medida tiene su ámbito propio de aplicación, pudiendo, según los casos, ser más o menos versátiles para desplegar la eficacia que de ellas se espera. Frente al cumplimiento de una obligación de hacer serán idóneas determinadas medidas y otras podrán no serlo, y lo mismo puede decirse respecto del cumplimiento de una obligación de no hacer. Así, la multa coercitiva será idónea tanto para vencer la resistencia al cumplimiento de una obligación de hacer como ante el incumplimiento de una obligación de no hacer. Por su parte, la ejecución

34 Díez-Picazo (2017).

35 En este sentido, Villaverde Menéndez (2016: 647 y 662, nota 23). 
sustitutoria puede ser idónea en relación con una obligación de hacer, ya que posibilita la sustitución de quien tiene que hacer y no hace por otro que lo hace, aunque no lo será ante el incumplimiento de una obligación de no hacer. Por último, la suspensión de funciones de la autoridad o funcionario puede ser adecuada cuando se incumple una obligación de no hacer, pues con la suspensión se evita que el obligado a no hacer pueda seguir incumpliendo, pero no parece que sea la más apropiada cuando se trate del cumplimiento de una obligación de hacer. De ahí que la conjunción e interrelación de las medidas de ejecución previstas permita diversas posibilidades de decisión ante cada caso concreto.

En definitiva, el Tribunal en manera alguna ha abdicado del ejercicio de su función de control de constitucionalidad al haber descartado, en términos abstractos y generales, la pretendida inconstitucionalidad de las medidas referidas, ya que ese control permanece bajo su dominio y responsabilidad plena. Y, por eso mismo, no deja de parecerme un tanto inexplicable que las nuevas facultades que le han sido atribuidas hayan venido a suscitar tantos reparos y recelos.

\section{Bibliografía}

Almeida Cerrada, M. (2017). La reforma del sistema de ejecución de las resoluciones del Tribunal Constitucional. El Cronista del Estado Social y Democrático de Derecho, 70, 66-75.

Arzoz Santisteban, X. (2016). Los poderes de ejecución de los Tribunales constitucionales alemán y austriaco. Revista Española de Derecho Constitucional, 108, 13-49. Disponible en: https://doi.org/10.18042/cepc/redc.108.01.

Cámara Villar, G. y Montilla Martos, J. A. (2015). Insólita reforma. El País, 9-9-2015. Disponible en: https://goo.gl/u85FxD.

Díez-Picazo, I. (2017). Breves reflexiones sobre la ejecución y compulsión al cumplimiento de las resoluciones del Tribunal Constitucional. Tribuna. Revista de Jurisprudencia, 1. Disponible en: https:/goo.gl/7ik3Sc.

Huergo Lora, A. (2007). Las sanciones administrativas. Madrid: Iustel.

López Aguilar, J. F. (2016). Cuestión catalana y crisis constitucional. Teoría y Realidad Constitucional, 37, 273-308.

Ridao Martín, J. (2016). Las nuevas facultades ejecutivas del Tribunal Constitucional como sustitutivo funcional de los mecanismos de coerción del artículo 155 de la Constitución. Revista Vasca de Administración Pública, 106, 151-188.

- (2017). La reforma del procedimiento de ejecución en la Ley del Tribunal Constitucional. La forja de una jurisdicción constitucional judicialista. El Cronista del Estado Social y Democrático de Derecho, 65, 52-61.

Roig Molés, E. y Nieva Fenoll, J. (2017). El Tribunal Constitucional y sus nuevas, e insólitas, facultades de ejecución: un duro golpe a su auctoritas. Diario La Ley, 8892. 
Santamaría Pastor, J. A. (2010). Comentario a la Ley reguladora de la Jurisdicción Contencioso-Administrativa. Madrid: Iustel.

Tomás y Valiente, F (1997). Discurso en sesión solemne del Tribunal con motivo de su $6^{\circ}$ aniversario. En Obras Completas, III (pp. 2283-2288). Madrid: Centro de Estudios Políticos y Constitucionales.

Villaverde Menéndez, I. (2016). Cumplir o ejecutar. La ejecución de sentencias del Tribunal Constitucional y su reciente reforma. Teoría y Realidad Constitucional, 38, 643-682. 